\title{
Lodo de esgoto e adubação mineral na recuperação de atributos químicos de solo degradado
}

\author{
Carolina S. B. Bonini ${ }^{1}$, Marlene C. Alves ${ }^{2} \&$ Rafael Montanari ${ }^{3}$
}

\section{Palavras-chave: \\ solo degradado \\ Eucalyptus citriodora \\ Brachiaria decumbens}

\begin{abstract}
R E S U M O
Objetivou-se, neste trabalho, estudar a influência do lodo de esgoto e adubação mineral na recuperação de atributos químicos de um Latossolo Vermelho degradado, cultivado há quatro anos, com eucalipto e braquiária. O delineamento experimental utilizado foi inteiramente casualizado com seis tratamentos e quatro repetições. Os tratamentos foram: T: testemunha (solo cultivado com eucalipto e braquiária sem uso do lodo de esgoto e adubação mineral); AM: solo cultivado com eucalipto e braquiária com adubação mineral; D30: solo cultivado com eucalipto e braquiária com $30 \mathrm{Mg} \mathrm{ha}^{-1}$ de lodo de esgoto; D60: solo cultivado com eucalipto e braquiária com $60 \mathrm{Mg} \mathrm{ha}^{-1}$ de lodo de esgoto e duas áreas foram utilizadas como testemunhas: VN: vegetação nativa do cerrado e SE: solo exposto. Foram avaliados os atributos químicos do solo: fósforo, potássio, cálcio, magnésio, matéria orgânica; acidez potencial, $\mathrm{pH}$, soma de bases, capacidade de troca catiônica e saturação por bases, em quatro camadas do solo: 0-0,05; 0,05-0,10; 0,10-0,20 e 0,20-0,40 m. Os resultados indicaram que ocorreram efeitos positivos do lodo de esgoto quanto à recuperação dos atributos químicos do solo.
\end{abstract}

Key words:

degraded soil

Eucalyptus citriodora

Brachiaria decumbens

\section{Sewage sludge and mineral fertilization on recovery of chemical properties of a degraded soil}

\begin{abstract}
A B S T R A C T
The objective of this work was to study the influence of sewage sludge and of mineral fertilization on recovery of chemical properties of a degraded Oxisol, cultivated for four years with eucalyptus and pasture, in Selvíria, MS, Brazil. The treatments were: T: control (soil under eucalyptus and pasture without the use of sewage sludge and mineral fertilizers): AM: soil under eucalyptus and pasture with mineral fertilization; D30: soil under eucalyptus and pasture with $30 \mathrm{Mg} \mathrm{ha}^{-1}$ of sewage sludge; D60: soil under eucalyptus and pasture with $60 \mathrm{Mg} \mathrm{ha}^{-1}$ of sewage sludge; and two control areas: VN: Native 'Cerrado' vegetation and SE: Bare soil (no tillage and without planting). Soil samples were collected in four soil layers ( 0 to $0.05,0.05-0.10,0.10-0.20$ and $0.20-0.40 \mathrm{~m}$ ) and evaluated for the chemical attributes: phosphorus, organic matter, $\mathrm{pH}$ and base saturation. It is concluded that there were positive effects of sewage sludge on the recovery of chemical properties of soil.
\end{abstract}

Protocolo 066-2014 - 26/02/2014 • Aprovado em 05/12/2014 • Publicado em 02/03/2015

${ }^{1}$ Curso de Engenharia Agronômica/Faculdade de Dracena/UNESP. Dracena, SP. E-mail: carolbonini@dracena.unesp.br (Autora correspondente)

${ }^{2}$ DEFERS/FEIS/UNESP. Ilha Solteira, SP. E-mail: mcalves@agr.feis.unesp.br

${ }^{3}$ DEFERS/FEIS/UNESP. Ilha Solteira, SP. E-mail: rafamontana@hotmail.com 


\section{INTRODUÇÃo}

O uso do lodo de esgoto ainda é, na agricultura, um assunto bastante questionado devido aos danos que pode causar à saúde humana e ao meio ambiente, além de prejuízos financeiros, se utilizado de forma incorreta.

O emprego do lodo de esgoto como adubo orgânico na recuperação de solos degradados, torna-se uma alternativa para a disposição final deste resíduo sendo também recomendada sua aplicação como fertilizante e condicionador de solos, por ser rico em matéria orgânica (MO) e nutrientes (Barboza \& Tavares Filho, 2006; Alves et al, 2007;. Kitamura et al., 2008), melhorando a qualidade de solos de baixa fertilidade (Pedroza et al., 2010).

Em experimentos realizados por Campos \& Alves (2008) observou-se, para a cultura do eucalipto, que o lodo de esgoto apresentou potencial para substituir fertilizantes minerais.

A definição da degradação do solo está associada à própria definição de qualidade do solo, ou seja, à medida que as características são alteradas negativamente, estabelece-se um processo de degradação (Alves \& Souza, 2008).

A degradação química do solo, segundo Bonini (2012) resulta na queda de sua fertilidade, ocasionada pela redução dos teores e da qualidade da matéria orgânica e pela redução dos teores de macro e micronutrientes. Comumente, há aumento dos teores de $\mathrm{Mn}$ e $\mathrm{Al}$, devido à redução do $\mathrm{pH}$. Referidos atributos constituem indicadores importantes da qualidade do solo.

Vários autores têm estudado a influência de uso de resíduo industriais na recuperação da qualidade química do solo (Suzuki \& Alves, 2006; Colodro \& Espíndola, 2006; Rodrigues et al., 2007; Ricci et al., 2010) verificaram que o lodo de esgoto se tem destacado no incremento de bases trocáveis e matéria orgânica do solo.

Barboza \& Tavares Filho (2006) reforçam que o uso do lodo de esgoto na agricultura deve estar condicionado às regras que definam as exigências de qualidade do material a ser reciclado e aos cuidados exigidos para estabilização, desinfecção e normas de utilização que incluam as restrições de uso, descritos na resolução CONAMA 375 (Brasil, 2006). Os resultados com seu uso em recuperação em áreas degradadas proporcionam o rápido estabelecimento e crescimento da vegetação e melhor desenvolvimento radicular, além de minimizar custos com adubação mineral.

Alguns estudos relatam a relação direta da matéria orgânica sobre a capacidade de troca catiônica (CTC) do solo (Colodro \& Espíndola, 2006; Rodrigues et al., 2007; Ricci et al, 2010; Schiavoni et al, 2011; Bonini, 2012; Costa et al., 2014).

Segundo Rodrigues et al. (2007) com base na capacidade de regeneração de um subsolo em área remanescente da construção de Usina Hidrelétrica de Ilha Solteira, SP, da qual foram removidos quase $10 \mathrm{~m}$ de solo, observou-se que a capacidade de troca catiônica é influenciada pelo teor de matéria orgânica fornecido pelo lodo de esgoto até a camada de $0,20 \mathrm{~m}$. Em profundidades maiores a capacidade de troca catiônica deixa de ser influenciada pelos teores de matéria orgânica. Junto com a matéria orgânica e a capacidade de troca catiônica, a soma de bases e a saturação por bases decrescem em profundidade visto que a maior parte dos nutrientes é proveniente da vegetação e está relacionada aos teores de matéria orgânica do solo.

Alves et al. (2007) estudaram a recuperação de solo de área remanescente de obra civil (Usina Hidrelétrica) e notaram melhorias na qualidade do solo quando efetuados seu preparo e a adição de lodo de esgoto e utilização de adubação verdes. Kitamura et al. (2008) verificaram a recuperação de atributos químicos do solo em área de estudo degradada também por retirada de solo para construção de barragem utilizando adubação verde, lodo de esgoto e braquiária, em que o lodo de esgoto se mostrou eficaz em curto prazo.

Para o comportamento do teor de fosforo no solo, Costa et al. (2014) verificaram que o uso de lodo de esgoto distribuído manualmente e incorporado à camada de $0,10 \mathrm{~m}$ com auxílio da enxada rotativa, durante 6 anos com ate 10 dias antes da semeadura da cultura do milho influenciou positivamente nos atributos químicos do solo $(\mathrm{pH}$, fosforo, capacidade de troca catiônica, matéria orgânica).

Com isto, o objetivo neste trabalho foi estudar a recuperação dos atributos químicos de um Latossolo Vermelho degradado, remanescente de uma área da qual foi retirado solo para terraplanagem e fundação da construção da Usina Hidroelétrica de Ilha Solteira, SP, utilizando-se lodo de esgoto e adubação mineral.

\section{Material e Métodos}

A área experimental é pertencente à Faculdade de Engenharia da Universidade Estadual Paulista, em Selvíria, MS, a $20^{\circ} 22^{\prime} \mathrm{S}, 51^{\circ} 22^{\prime} \mathrm{W}$ e altitude de $335 \mathrm{~m}$. O solo é classificado como Latossolo Vermelho distrófico (EMBRAPA, 2013), de textura média (Alves \& Souza, 2008).

O clima da região, de acordo com Köppen, é definido como tropical úmido (Aw), com estação chuvosa no verão e seca no inverno. As médias anuais de temperatura e precipitação pluvial são de $23,5^{\circ} \mathrm{C}$ e $1.370 \mathrm{~mm}$ e a umidade relativa do ar fica entre 70 e $80 \%$ (Demattê, 1980).

O experimento fica localizado em uma área degradada de onde foi retirada uma camada de solo de aproximadamente 8,60 $m$ de espessura para utilização na terraplanagem e fundação da construção da Usina Hidrelétrica de Ilha Solteira, SP.

O delineamento experimental utilizado foi inteiramente casualizado com seis tratamentos e quatro repetições totalizando 24 parcelas com área de $200 \mathrm{~m}^{2}(10 \times 20 \mathrm{~m})$ e o espaçamento entre blocos foi de $5 \mathrm{~m}$. A cultura do eucalipto (Eucalyptus citriodora Hook) foi plantada com espaçamento de $4 \times 2 \mathrm{~m}$.

Os tratamentos instalados em fevereiro de 2003 foram: $\mathrm{T}$ Testemunha (solo cultivado com eucalipto e braquiária sem uso do lodo de esgoto e adubação mineral); AM - Solo cultivado com eucalipto e braquiária com adubação mineral; D30 - Solo cultivado com eucalipto e braquiária com $30 \mathrm{Mg} \mathrm{ha}^{-1}$ de lodo de esgoto; D60 - Solo cultivado com eucalipto e braquiária com $60 \mathrm{Mg} \mathrm{ha}^{-1}$ de lodo de esgoto e duas áreas testemunhas: VN - Vegetação nativa do cerrado e SE - Solo exposto.

A caracterização química da área experimental foi realizada em dezembro de 2002, antes da implantação do experimento e da subsolagem. Foram coletadas amostras simples em vinte pontos da área experimental formando uma amostra composta 
por camada de solo $(0-0,05 ; 0,05-0,10 ; 0,10-0,20$ e $0,20-0,40$ $\mathrm{m})$. Foram avaliados os teores de fósforo, potássio, magnésio e cálcio, pelo método de extração com resina trocadora de íons. O teor de matéria orgânica foi determinado pelo método colorimétrico e o $\mathrm{pH}$, em cloreto de cálcio, além da acidez potencial (hidrogênio + alumínio) a pH 7,0. Foram calculadas as somas de bases $(\mathrm{SB}=\mathrm{Ca}+\mathrm{Mg}+\mathrm{K})$, capacidade de troca catiônica $(\mathrm{CTC}=\mathrm{SB}+(\mathrm{H}+\mathrm{Al}))$ e saturação por bases $(\mathrm{V} \%=$ (100 x SB) / CTC). As análises foram realizadas de acordo com a metodologia descrita em Raij \& Quaggio (1983).

O lodo de esgoto foi obtido da SANEAR, Saneamento de Araçatuba, localizada no município de Araçatuba, SP. As análises do lodo de esgoto (propriedades químicas) foram realizadas pelo laboratório de nutrição de plantas da Universidade Estadual Paulista (UNESP) de Ilha Solteira, SP; as análises de metais pesados e análise parasitológica foram realizadas pelo laboratório de Microbiologia da Univesidade Federal do Paraná (UFPR) (Tabelas 2 a 4). Todas as análises foram realizadas antes da aplicação do lodo de esgoto na area experimental.

O lodo de esgoto utilizado é resultante do tratamento de efluente predominantemente doméstico, com umidade de $0,84 \mathrm{~kg} \mathrm{~kg}^{-1}$. Os teores de metais pesados foram baixos e para alguns elementos nulos. As características microbiológicas do lodo de esgoto, de acordo com a ETE de Araçatuba, foram: Coliformes totais: $2,3.10^{8} \mathrm{NMP} \mathrm{g}^{-1}$ de lodo; Coliformes fecais: $1,4 \cdot 10^{2} \mathrm{NMP} \mathrm{g}^{-1}$ de lodo; Pesquisa positiva para Salmonella ssp: 3,2 NMP g-1 lodo e após 15 dias: Coliformes totais: 2,3 . $10^{8} \mathrm{NMP} \mathrm{g}^{-1}$ de lodo; Coliformes fecais: $1,4.10^{2} \mathrm{NMP} \mathrm{g}^{-1} \mathrm{de}$ lodo; Pesquisa positiva para Salmonella ssp: $3,2 \mathrm{NMP} \mathrm{g}^{-1}$ lodo e foram realizadaos pelo Labortechnic Tecnologia, São Paulo, SP

O plantio da cultura de eucalipto e a semeadura da braquiária foram efetuados em março de 2003.

Para obter uma boa descompactação mecânica do solo foram realizadas duas subsolagens cruzadas atingindo a profundidade de $0,40 \mathrm{~m}$. Para a correção da acidez do solo foram aplicados $800 \mathrm{~kg}$ de calcário dolomítico; o mesmo foi incorporado com grade leve em toda a área experimental, antes da aplicação do lodo de esgoto e do plantio do eucalipto.

Nas parcelas com fertilizante mineral foram aplicadas as seguintes doses de nutrientes: $20 \mathrm{~kg} \mathrm{ha}^{-1}$ de nitrogênio, $90 \mathrm{~kg}$ $\mathrm{ha}^{-1}$ de fósforo e $20 \mathrm{~kg} \mathrm{ha}^{-1}$ de potássio. Em cobertura foram aplicados $39 \mathrm{~kg} \mathrm{ha}^{-1}$ de nitrogênio e $39 \mathrm{~kg} \mathrm{ha}^{-1}$ de potássio divididos em três vezes de $13,0 \mathrm{~kg} \mathrm{ha}^{-1}$ no ano.

O lodo de esgoto foi aplicado na superfície, um mês antes do plantio do eucalipto e semeadura da braquiária, sendo o mesmo distribuído manualmente; em seguida, o resíduo foi incorporado com enxada rotativa a uma profundidade de 0,10 m. O lodo, depois de distribuído, permaneceu exposto por sete dias sob efeito da radiação solar e de temperaturas entre 35 a $40{ }^{\circ} \mathrm{C}$. O objetivo deste manejo foi reduzir o teor de nitrogênio orgânico a partir da volatilização do excesso de amônia. De acordo com Mello et al. (1983) algumas condições favorecem a volatilização da amônia: temperaturas elevadas, déficit de
Tabela 2. Metais pesados - Natureza do trabalho: Ensaio na massa bruta

\begin{tabular}{llcc}
\hline \multicolumn{1}{c}{ Parâmetro } & Unidade & Resultado & Limite máximo \\
Arsênio & $\mathrm{mg} \mathrm{kg}^{-1}$ & $\mathrm{Nd}$ & 1000 \\
Berílio & $\mathrm{mg} \mathrm{kg}^{-1}$ & $\mathrm{Nd}$ & 100 \\
Chumbo & $\mathrm{mg} \mathrm{kg}^{-1}$ & 0,97 & 100 \\
Cianeto & $\mathrm{mg} \mathrm{kg}^{-1}$ & $\mathrm{Nd}$ & 1000 \\
Cromohexavalente & $\mathrm{mg} \mathrm{kg}^{-1}$ & 2,0 & 100 \\
Fenol & $\mathrm{mg} \mathrm{kg}^{-1}$ & $\mathrm{Nd}$ & 10 \\
Óleos e graxas & $\mathrm{mg} \mathrm{kg}^{-1}$ & 1,30 & - \\
Mercúrio & $\mathrm{mg} \mathrm{kg}^{-1}$ & $\mathrm{Nd}$ & 100 \\
Selênio & $\mathrm{mg} \mathrm{kg}^{-1}$ & $\mathrm{Nd}$ & 100 \\
Vanádio & $\mathrm{mg} \mathrm{kg}^{-1}$ & $\mathrm{Nd}$ & 1000 \\
\hline
\end{tabular}

Métodos de análises baseados na $20^{\mathrm{a}}$ edição do "Standard metods for the examination of water and wastewater"; Análises efetuadas segundo a NBR 10.004 - Resíduos sólidos; $\mathrm{Nd}$ - Não detectado; *Limite para teor de chumbo: compostos orgânicos: $100 \mathrm{mgPb} \mathrm{kg}^{-1}$; compostos minerais: $1000 \mathrm{mgPb} \mathrm{kg}^{-1}$

Tabela 3. Análise parasitológica do lodo de esgoto

\begin{tabular}{|c|c|c|c|}
\hline \multirow{2}{*}{ Helminto } & \multicolumn{2}{|c|}{ Média } & \multirow{2}{*}{ Total } \\
\hline & Viáveis & Inviáveis & \\
\hline Ascaris sp. & 0,04 & 0,16 & \\
\hline Trichuris sp. & & 0,24 & \\
\hline Toxocara sp. & & 0,08 & \\
\hline Trichuroidea & & 0,04 & \\
\hline Hymenolepis diminuta & & 0,12 & \\
\hline Total & 0,04 & 0,64 & 0,68 \\
\hline \multicolumn{4}{|l|}{$\%$ viabilidade } \\
\hline Observação & \multicolumn{3}{|c|}{ Cistos de protozoários $=0,04$} \\
\hline
\end{tabular}

Número total de ovos de Helmintos $=0,68$ ovos de helmintos por grama de matéria seca; Número de ovos viáveis $=0,04$ ovos por grama de matéria seca; Percentual de viabilidade $=0,32 \%$; Metodologia: Soccol et al. (2000); 0 resultado apresenta a média das análises feitas em triplicata. Viáveis - Reprodutivos; Não viáveis - Não reprodutivos

Tabela 4. Análise parasitológica do lodo de esgoto após 15 dias

\begin{tabular}{lccc}
\hline \multirow{2}{*}{ Helminto } & \multicolumn{2}{c}{ Média } & Total \\
\cline { 2 - 3 } & Viáveis & Inviáveis & geral \\
Ascaris sp. & 0 & 0,04 & 0,04 \\
Trichuris sp. & 0 & 0,15 & 0,15 \\
Toxocara sp. & 0 & 0,04 & 0,04 \\
Hymenolepis diminuta & 0 & 0,12 & 0,12 \\
Total & 0 & 0,35 & 0,35 \\
\% viabilidade & 0 & 0 & 0 \\
Observação & \multicolumn{2}{c}{ Cistos de protozoários $=0,04$} \\
\hline
\end{tabular}

Número total de ovos de Helmintos $=0,35$ ovos de helmintos por grama de matéria seca; Número de ovos viáveis $=0$ ovos por grama de matéria seca; Percentual de viabilidade $=0$ \%. Metodologia: Soccol et al. (2000); 0 resultado apresenta a média das análises feitas em triplicata. Viáveis - Reprodutivos; Não viáveis - Não reprodutivos

saturação do ar, baixo teor de água, rápida evaporação de água, baixa capacidade de troca catiônica e forma de aplicação do lodo.

As amostras para a análise química do solo foram coletadas em janeiro de 2007, nas camadas de 0-0,05; 0,050,$10 ; 0,10-0,20$ e $0,20-0,40 \mathrm{~m}$. A metodologia usada foi citada anteriormente quando da descrição da caracterização química incial do solo.

Os dados foram analisados efetuando-se a análise de variância e o teste de Tukey para as comparações de média no nível de 0,05 de probabilidade. Foi utilizado o programa computacional SISVAR 4.2 (Ferreira, 2008) para a realização da análise estatística.

Tabela 1. Propriedades químicas do lodo de esgoto utilizado

\begin{tabular}{|c|c|c|c|c|c|c|c|c|c|c|c|c|}
\hline \multirow{2}{*}{$\underset{g d^{-3}}{M O}$} & $\mathbf{N}$ & $P$ & K & $\mathrm{Ca}$ & $\mathrm{Mg}$ & S & B & $\mathrm{Cu}$ & $\mathrm{Fe}$ & $\mathrm{Mn}$ & $\mathrm{Zn}$ & \multirow{2}{*}{$\begin{array}{l}\text { Umidade } \\
\mathrm{kg} \mathrm{kg}^{-1}\end{array}$} \\
\hline & \multicolumn{6}{|c|}{$\mathrm{g} \mathrm{kg}^{-1}$} & \multicolumn{5}{|c|}{$\mathrm{mg} \mathrm{kg}^{-1}$} & \\
\hline 200 & 71,26 & 18,79 & 15,14 & 11,06 & 3,44 & 7,78 & 16,37 & 160,04 & 960,6 & 115,74 & 583,48 & 0,84 \\
\hline
\end{tabular}




\section{Resultados e Discussão}

Os resultados da caracterização química do solo antes do preparo do solo, estão apresentados na Tabela 5.

Os valores médios de fósforo $(\mathrm{P})$, potássio $(\mathrm{K})$, cálcio (Ca) e magnésio $(\mathrm{Mg})$, matéria orgânica $(\mathrm{MO})$, potencial hidrogeniônico $(\mathrm{pH})$, acidez potencial $(\mathrm{H}+\mathrm{Al})$, soma de bases (SB), capacidade de troca catiônica (CTC) e saturação por bases (V\%) nas camadas de solos de $0,00-0,05 ; 0,05-0,10$; 0,10-0,20 e 0,20-0,40 m, estão apresentados nas Tabelas 6 e 7, respectivamente.

Para o teor de fósforo $(\mathrm{P})$ o efeito foi significativo entre os tratamentos, em todas as camadas estudadas e o maior valor de $\mathrm{P}$ foi verificado na área cultivada com eucalipto e tratada com a dose de $60 \mathrm{Mg} \mathrm{ha}^{-1}$ de lodo de esgoto, seguido da área tratada com a dose de $30 \mathrm{Mg} \mathrm{ha}^{-1}$ (Tabelas 6 e 7). Na camada superficial ocorreu aumento no teor de $\mathrm{P}$ concordando com resultados encontrados por Costa et al. (2014) que verificaram aumento considerável do teor de $\mathrm{P}$ no solo com o uso de lodo de esgoto, que foi incorporado ao solo manualmente e até a camada $0,10 \mathrm{~m}$, com o auxílio de enxada, nos anos de 2001 a 2006, entre 5 a 10 dias antes da semeadura do milho.

Resultados deste trabalho concordam com os verificados por Colodro \& Espíndola (2006) que estudaram a recuperação do solo na mesma área da pesquisa e observaram que as doses de lodo de esgoto de 30 e $60 \mathrm{Mg} \mathrm{ha}^{-1}$ aumentaram o teor de $\mathrm{P}$ no solo. $\mathrm{O}$ aumento significativo estatisticamente do $\mathrm{P}$ no solo pode ser explicado pela disponibilização deste elemento uma vez que, com as doses de 30 e $60 \mathrm{Mg} \mathrm{ha}^{-1}$ foram adicionados 560 e $1127 \mathrm{~kg}$ de P. Alves \& Souza (2008) analisaram atributos químicos em área degradada em recuperação por cinco anos, com adubos verdes, calcário e gesso verificaram que houve incremento no teor de $\mathrm{P}$ de 70 e $50 \%$ na camada superficial e subsuperficial, respectivamente.

Em Suzuki \& Alves (2006) foi observado, na recuperação de áreas degradadas por construção civil, que após um ano de implantação dos adubos verdes, não foi observado efeito das coberturas do solo no incremento de seus atributos químicos devido à rápida decomposição dos resíduos de plantas de cobertura (leguminosas).

Para os cátions trocáveis $(\mathrm{Ca}, \mathrm{Mg}$ e $\mathrm{K}$ ) verificou-se que nas camadas estudadas houve efeito significativo entre os tratamentos; para o $\mathrm{Ca}$, o maior teor encontrado foi na área cultivada com eucalipto e tratado com dose de $60 \mathrm{Mg} \mathrm{ha}^{-1}$, sendo que o valor encontrado é semelhante ao contido na vegetação natural, na camada de 0,00-0,05 m; nas demais foram encontrados valores muito baixos. $\mathrm{O}$ valor de $\mathrm{Mg}$ foi maior nos tratamentos de recuperação (AM, D30 e D60) pelo fato de ter sido realizada a calagem com calcário dolomítico.

$\mathrm{O}$ incremento nos teores de $\mathrm{Ca}$ e $\mathrm{Mg}$ foi verificado por Ricci et al. (2010) no tratamento que recebeu $80 \mathrm{Mg} \mathrm{ha}^{-1} \mathrm{de}$ lodo de esgoto. Contudo, para o $\mathrm{K}$, valores semelhantes aos encontrados neste trabalho foram verificados por Berton et al. (1989), Muraishi et al. (2011).

Tabela 5. Características químicas do solo degradado antes do preparo, em dezembro de 2002

\begin{tabular}{|c|c|c|c|c|c|c|c|c|c|c|c|}
\hline \multirow{2}{*}{$\begin{array}{c}\text { Camada } \\
\text { (m) }\end{array}$} & \multirow{2}{*}{$\begin{array}{l}P_{\text {resina }} \\
\mathbf{m g ~ d m}^{-3}\end{array}$} & \multirow{2}{*}{$\begin{array}{c}\text { MO } \\
\text { g dm }{ }^{-3}\end{array}$} & \multirow{2}{*}{ pH } & $K$ & $\mathrm{Ca}$ & $\mathrm{Mg}$ & $\mathrm{H}+\mathrm{Al}$ & Al & SB & CTC & V \\
\hline & & & & \multicolumn{7}{|c|}{$\mathrm{mmol}_{\mathrm{c}} \mathrm{dm}^{-3}$} & $\%$ \\
\hline $0-0,05$ & 1 & 5 & 4,5 & 0,6 & 4 & 2 & 15 & 1 & 6,6 & 21,6 & 31 \\
\hline $0,05-0,10$ & 1 & 4 & 4,6 & 0,1 & 4 & 2 & 15 & 1 & 6,1 & 21,1 & 29 \\
\hline $0,10-0,20$ & 2 & 3 & 4,7 & 0,1 & 4 & 2 & 15 & 1 & 6,1 & 21,1 & 29 \\
\hline $0,20-0,40$ & 2 & 3 & 4,5 & 0,1 & 3 & 2 & 15 & 1 & 5,1 & 20,1 & 25 \\
\hline
\end{tabular}

Tabela 6. Valores médios de teor de fósforo $(\mathrm{P})$, potássio $(\mathrm{K})$, cálcio $(\mathrm{Ca})$ e magnésio $(\mathrm{Mg})$, matéria orgânica $(\mathrm{MO})$, potencial hidrogeniônico $(\mathrm{pH})$, acidez potencial $(\mathrm{H}+\mathrm{Al})$, soma de bases $(\mathrm{SB})$, capacidade de troca catiônica $(\mathrm{CTC})$ e saturação por bases $(\mathrm{V} \%)$ para os tratamentos estudados, nas camadas de 0-0,05 e 0,05-0,10 m

\begin{tabular}{|c|c|c|c|c|c|c|c|c|c|c|}
\hline \multirow{2}{*}{ Tratamentos } & $\mathbf{P}$ & $\bar{K}$ & $\mathrm{Ca}$ & $\mathrm{Mg}$ & \multirow{2}{*}{$\begin{array}{c}\mathrm{MO} \\
\mathrm{g} \mathrm{dm^{-3 }}\end{array}$} & \multirow{2}{*}{ pH } & $\mathrm{H}+\mathrm{Al}$ & SB & CTC & \multirow{2}{*}{$\begin{array}{l}\mathbf{V} \\
\%\end{array}$} \\
\hline & $\mathrm{mg} \mathrm{dm}^{-3}$ & \multicolumn{3}{|c|}{$\mathrm{mmol}_{\mathrm{c}} \mathrm{dm}^{-3}$} & & & \multicolumn{3}{|c|}{$\mathrm{mmol}_{\mathrm{G}} \mathrm{dm}^{-3}$} & \\
\hline & \multicolumn{10}{|c|}{$0-0,05 \mathrm{~m}$} \\
\hline$T$ & $1 \mathrm{c}$ & $0,5 \mathrm{c}$ & $6 \mathrm{~b}$ & $8 b$ & $9 \mathrm{c}$ & $5,6 \mathrm{~b}$ & $11 \mathrm{~d}$ & $14,5 \mathrm{~b}$ & $25,5 \mathrm{c}$ & $57 \mathrm{a}$ \\
\hline AM & $14 \mathrm{C}$ & $0,6 \mathrm{c}$ & $6 b$ & $13 \mathrm{a}$ & $10 \mathrm{c}$ & $5,9 \mathrm{a}$ & $11 \mathrm{~d}$ & $19,6 \mathrm{~b}$ & $30,6 \mathrm{~b}$ & $64 \mathrm{a}$ \\
\hline D30 & $55 \mathrm{~b}$ & $0,7 \mathrm{~b}$ & $9 \mathrm{ab}$ & $13 \mathrm{a}$ & $15 \mathrm{~b}$ & $5,2 \mathrm{~b}$ & $16 \mathrm{c}$ & $22,7 \mathrm{a}$ & $38,7 \mathrm{~b}$ & $57 \mathrm{a}$ \\
\hline D60 & $97 \mathrm{a}$ & $0,7 \mathrm{~b}$ & $13 a$ & $14 \mathrm{a}$ & $16 \mathrm{~b}$ & $4,8 \mathrm{C}$ & $21 \mathrm{~b}$ & $27,7 \mathrm{a}$ & $48,7 \mathrm{a}$ & $57 a$ \\
\hline VN & $6 \mathrm{c}$ & $1,6 \mathrm{a}$ & $10 \mathrm{a}$ & $7 \mathrm{~b}$ & $31 \mathrm{a}$ & $4,6 \mathrm{c}$ & $31 \mathrm{a}$ & $18,6 \mathrm{~b}$ & $49,6 \mathrm{a}$ & $37 \mathrm{~b}$ \\
\hline SE & $2 c$ & $0,3 \mathrm{~d}$ & $2 \mathrm{c}$ & $1 \mathrm{c}$ & $3 d$ & $4,4 \mathrm{C}$ & $13 \mathrm{c}$ & $3,3 \mathrm{~b}$ & $16,3 d$ & $21 \mathrm{c}$ \\
\hline $\mathrm{F}$ & $25,30^{*}$ & $97,34^{*}$ & $4,63^{*}$ & $14,09 *$ & $85,34^{*}$ & $18,57^{*}$ & $70,55^{*}$ & $8,61^{*}$ & $25,59 *$ & $26,05^{*}$ \\
\hline CV $(\%)$ & 16,67 & 12,67 & 26,78 & 19,01 & 14,73 & 5,33 & 10,38 & 21,50 & 13,56 & 14,80 \\
\hline \multirow[t]{2}{*}{ DMS $-5 \%$} & 24,850 & 0,210 & 6,980 & 6,360 & 4,780 & 0,622 & 4,160 & 13,270 & 11,160 & 16,440 \\
\hline & \multicolumn{10}{|c|}{$0,05-0,10 \mathrm{~m}$} \\
\hline $\mathrm{T}$ & $1 \mathrm{c}$ & $0,4 \mathrm{bc}$ & $7 \mathrm{~b}$ & $6 \mathrm{~b}$ & $8 \mathrm{~b}$ & $5,8 \mathrm{~b}$ & $11 \mathrm{c}$ & $13,4 \mathrm{~b}$ & $24,4 \mathrm{~b}$ & $55 b$ \\
\hline AM & $5 \mathrm{c}$ & $0,6 \mathrm{~b}$ & $6 \mathrm{~b}$ & $12 \mathrm{a}$ & $7 \mathrm{~b}$ & $6,4 \mathrm{a}$ & $9 \mathrm{c}$ & $18,6 a b$ & $27,8 a b$ & $67 \mathrm{a}$ \\
\hline D30 & $39 \mathrm{~b}$ & $0,5 b$ & $7 \mathrm{~b}$ & $8 b$ & $9 \mathrm{~b}$ & $5,1 \mathrm{~b}$ & $15 b$ & $15,5 b$ & $30,5 a b$ & $51 \mathrm{~b}$ \\
\hline D60 & $98 \mathrm{a}$ & $0,5 b$ & $11 \mathrm{a}$ & $10 \mathrm{a}$ & $10 \mathrm{~b}$ & $4,8 \mathrm{~b}$ & $19 b$ & $21,5 \mathrm{a}$ & $40,5 \mathrm{a}$ & $53 b$ \\
\hline VN & $4 c$ & $1,3 a$ & $3 c$ & $4 \mathrm{C}$ & $18 \mathrm{a}$ & $4,3 \mathrm{C}$ & $31 \mathrm{a}$ & $8,3 \mathrm{c}$ & $39,3 \mathrm{a}$ & $21 \mathrm{c}$ \\
\hline SE & $2 \mathrm{C}$ & $0,3 \mathrm{C}$ & $1 \mathrm{c}$ & $1 d$ & $1 \mathrm{C}$ & $4,4 \mathrm{C}$ & $15 b$ & $2,3 \mathrm{~d}$ & $17,3 \mathrm{c}$ & $13 \mathrm{C}$ \\
\hline $\mathrm{F}$ & $31,25^{\star}$ & $74,80^{\star}$ & $10,76^{\star}$ & $12,99^{*}$ & $94,58^{*}$ & $28,56^{\star}$ & $78,60^{*}$ & $12,41^{*}$ & $20,48^{*}$ & $37,60^{*}$ \\
\hline CV (\%) & 10,08 & 13,72 & 15,89 & 22,30 & 12,90 & 6,01 & 10,38 & 21,85 & 11,59 & 17,04 \\
\hline DMS - $5 \%$ & 14,560 & 0,180 & 5,330 & 5,230 & 2,620 & 0,709 & 4,020 & 10,250 & 8,220 & 16,980 \\
\hline
\end{tabular}

*Teste F significativo a 5\% de probabilidade; nsNão significativo; Médias seguidas de letras iguais na coluna não diferem entre si pelo teste de Tukey a 0,05 de probabilidade; T - Testemunha (solo cultivado com eucalipto e braquiária sem uso do lodo de esgoto e adubação mineral); AM - Solo cultivado com eucalipto e braquiária com adubação mineral; D30 - Solo cultivado com eucalipto e braquiária com $30 \mathrm{Mg} \mathrm{ha}^{-1}$ de lodo de esgoto; D60 - Solo cultivado com eucalipto e braquiária com 60 Mg ha-1 de lodo de esgoto; VN - Vegetação nativa do cerrado; SE - Solo exposto 
Tabela 7. Valores médios de teor de fósforo $(\mathrm{P})$, potássio $(\mathrm{K})$, cálcio $(\mathrm{Ca})$ e magnésio $(\mathrm{Mg})$, matéria orgânica $(\mathrm{MO})$, potencial hidrogeniônico $(\mathrm{pH})$, acidez potencial $(\mathrm{H}+\mathrm{Al})$, soma de bases $(\mathrm{SB})$, capacidade de troca catiônica (CTC) e saturação por bases $(\mathrm{V} \%)$ para os tratamentos estudados, nas camadas de 0,10-0,20 e 0,20-0,40 m

\begin{tabular}{|c|c|c|c|c|c|c|c|c|c|c|}
\hline \multirow{2}{*}{ Tratamentos } & \multirow{2}{*}{$\begin{array}{c}P \\
\mathrm{mg} \mathrm{dm}^{-3}\end{array}$} & $\bar{K}$ & $\mathrm{Ca}$ & \multirow[t]{2}{*}{$\mathrm{Mg}$} & \multirow{2}{*}{$\begin{array}{c}\mathrm{MO} \\
\mathrm{g} \mathrm{\textrm {dm } ^ { - 3 }}\end{array}$} & \multirow{2}{*}{ pH } & $\mathrm{H}+\mathrm{Al}$ & SB & CTC & \multirow{2}{*}{$\begin{array}{l}\mathbf{V} \\
\%\end{array}$} \\
\hline & & \multicolumn{2}{|c|}{$\mathrm{mmol}_{\mathrm{c}} \mathrm{dm}^{-3}$} & & & & \multicolumn{3}{|c|}{$\mathrm{mmol}_{\mathrm{G}} \mathrm{dm}^{-3}$} & \\
\hline & \multicolumn{10}{|c|}{$0,10-0,20 \mathrm{~m}$} \\
\hline T & $1 \mathrm{~b}$ & $0,3 \mathrm{c}$ & $8 a b$ & $6 \mathrm{a}$ & $5 \mathrm{bc}$ & $6,2 \mathrm{a}$ & $10 \mathrm{~d}$ & $14,3 \mathrm{a}$ & $24,3 a b$ & $59 a$ \\
\hline AM & $2 \mathrm{~b}$ & $0,5 \mathrm{~b}$ & $7 \mathrm{~b}$ & $7 \mathrm{a}$ & $4 \mathrm{C}$ & $6,3 \mathrm{a}$ & $9 \mathrm{~d}$ & $14,5 \mathrm{a}$ & $23,5 a b$ & $62 \mathrm{a}$ \\
\hline D30 & $6 \mathrm{~b}$ & $0,3 c$ & $5 \mathrm{~b}$ & $4 \mathrm{~b}$ & $6 \mathrm{bc}$ & $5,4 a b$ & $12 \mathrm{~cd}$ & $9,3 a$ & $21,3 b$ & $44 a$ \\
\hline D60 & $35 a$ & $0,2 \mathrm{c}$ & $10 \mathrm{a}$ & $8 a$ & $6 \mathrm{~b}$ & $5,1 \mathrm{bc}$ & $14 \mathrm{bc}$ & $18,2 \mathrm{a}$ & $32,2 \mathrm{a}$ & $57 a$ \\
\hline VN & $2 \mathrm{~b}$ & $0,7 \mathrm{a}$ & $1 \mathrm{c}$ & $2 c$ & $11 a$ & $4,1 \mathrm{~d}$ & $22 \mathrm{a}$ & $3,7 \mathrm{~b}$ & $25,7 a b$ & $14 b$ \\
\hline SE & $2 \mathrm{~b}$ & $0,3 \mathrm{~b}$ & $1 \mathrm{c}$ & $1 \mathrm{c}$ & $1 \mathrm{~d}$ & $4,3 \mathrm{~cd}$ & $15 b$ & $2,3 \mathrm{~b}$ & $17,3 \mathrm{c}$ & 13b \\
\hline $\mathrm{F}$ & $8,21^{*}$ & $14,72^{*}$ & $14,724^{*}$ & $8,61^{*}$ & $74,96^{\text {ns }}$ & $20,19^{*}$ & $52,27^{*}$ & $13,15^{*}$ & $10,56^{*}$ & $34,06 *$ \\
\hline CV $(\%)$ & 17,43 & 15,85 & 23,72 & 21,43 & 12,83 & 7,81 & 9,26 & 14,25 & 10,85 & 20,04 \\
\hline \multirow[t]{2}{*}{ DMS $-5 \%$} & 14,990 & 0,220 & 4,040 & 4,600 & 1,710 & 0,940 & 2,920 & 8,030 & 5,970 & 18,450 \\
\hline & \multicolumn{10}{|c|}{$0,20-0,40 \mathrm{~m}$} \\
\hline $\mathrm{T}$ & $1 \mathrm{c}$ & $0,2 \mathrm{c}$ & $5 \mathrm{a}$ & $3 a$ & $3 b$ & $5,0 \mathrm{~b}$ & $12 b c$ & $8,2 \mathrm{a}$ & $20,2 a b$ & $41 a$ \\
\hline AM & $2 \mathrm{~b}$ & $0,3 b$ & $3 b$ & $4 \mathrm{a}$ & $3 \mathrm{~b}$ & $5,6 \mathrm{~b}$ & $11 \mathrm{c}$ & $7,3 \mathrm{a}$ & $18,3 \mathrm{~b}$ & $40 \mathrm{a}$ \\
\hline D30 & $3 b$ & $0,1 \mathrm{C}$ & $4 \mathrm{~b}$ & $2 \mathrm{~b}$ & $3 \mathrm{~b}$ & $4,7 \mathrm{a}$ & $12 \mathrm{bc}$ & $6,1 b$ & $18,1 b$ & $34 \mathrm{~b}$ \\
\hline D60 & $4 a$ & $0,1 \mathrm{c}$ & $7 \mathrm{a}$ & $3 a$ & $3 b$ & $4,9 \mathrm{a}$ & $12 \mathrm{bc}$ & $10,1 \mathrm{a}$ & $22,1 \mathrm{a}$ & $46 a$ \\
\hline VN & $2 b$ & $0,5 \mathrm{a}$ & $0 \mathrm{C}$ & $1 \mathrm{~b}$ & $11 \mathrm{a}$ & $4,0 \mathrm{a}$ & $22 a$ & $1,5 c$ & $23,5 \mathrm{a}$ & $6 c$ \\
\hline SE & $2 b$ & $0,2 \mathrm{c}$ & $0 \mathrm{c}$ & $\mathrm{Ob}$ & $1 \mathrm{c}$ & $4,3 a$ & $15 b$ & $0,2 \mathrm{C}$ & $15,2 b$ & $2 c$ \\
\hline $\mathrm{F}$ & $4,37^{\star}$ & $16,50^{*}$ & $5,15^{\star}$ & $2,45^{\text {ns }}$ & $73,30^{\star}$ & $2,62^{\mathrm{ns}}$ & $30,66^{*}$ & $3,02^{*}$ & $4,83^{\star}$ & $4,72^{\star}$ \\
\hline CV (\%) & 12,21 & 19,96 & 22,14 & 18,88 & 6,32 & 14,53 & 10,92 & 21,56 & 12,90 & 24,63 \\
\hline DMS - $5 \%$ & 1,670 & 0,160 & 4,350 & 5,600 & 0,590 & 1,583 & 3,490 & 8,770 & 5,710 & 33,400 \\
\hline
\end{tabular}

*Teste F significativo a 5\% de probabilidade; ns Não significativo; Médias seguidas de letras iguais na coluna não diferem entre si pelo teste de Tukey a 0,05 de probabilidade; $\mathrm{T}$ - Testemunha (solo cultivado com eucalipto e braquiária sem uso do lodo de esgoto e adubação mineral); AM - Solo cultivado com eucalipto e braquiária com adubação mineral; D30 - Ssolo cultivado com eucalipto e braquiária com $30 \mathrm{Mg} \mathrm{ha}^{-1}$ de lodo de esgoto; D60 - Solo cultivado com eucalipto e braquiária com 60 Mg ha-1 de lodo de esgoto; VN - Vegetação nativa do cerrado; SE - Solo exposto

Para o teor de MO houve efeito significativo entre os tratamentos observando-se que o maior teor encontrado foi para a vegetação natural. Nas áreas cultivadas com eucalipto e tratadas com as doses de 30 e $60 \mathrm{Mg} \mathrm{ha}^{-1}$ constatouse incremento quando comparado com os tratamentos testemunha, adubação mineral e o solo exposto. Incrementos no teor de M.O foram encontrados por Kitamura et al. (2008) que, estudando a recuperação de áreas degradadas com adição de lodo de esgoto, adubação mineral e implantação de espécies nativas do cerrado, concordam com Colodro \& Espíndola (2006) que constataram que a adição de lodo promoveu aumento na matéria orgânica do solo; entretanto, não houve diferença entre as duas doses utilizadas (30 e $60 \mathrm{Mg} \mathrm{ha}^{-1}$ ).

O efeito da adição de material orgânico ao solo e consequentemente aumento no teor da MO, também foram verificados por Rodrigues et al. (2007) que trabalharam com a implantação de braquiária em áreas com até $10 \mathrm{~m}$ de solo retirado para a construção civil (subsolo). Schiavoni et al. (2011) não verificaram, trabalhando com fertilizante organomineral da indústria produtora dos aminoácidos lisina e treonina, efeitos sobre os atributos químicos do solo.

$\mathrm{O}$ incremento de $\mathrm{MO}$ no solo atua positivamente no processo de recuperação, quer seja por fornecer nutrientes a partir da mineralização e também na melhor estruturação do solo (qualidade física) que vai interferir na porosidade e na aeração do solo.

Verificou-se, para o $\mathrm{Ph}$, que nas camadas estudadas a área cultivada com eucalipto e tratada com a dose de $60 \mathrm{Mg} \mathrm{ha}^{-1}$ obteve resultados semelhantes aos verificados na vegetação natural. Os tratamentos testemunha e com adubação mineral incrementaram positivamente os valores de $\mathrm{pH}$ (Tabela 6). Resultados semelhantes foram observados por Colodro \& Espíndola (2006) que constataram verificaram que o lodo de esgoto não influenciou o $\mathrm{pH}$ do solo, por não ter sido acrescentado calcário para a redução de patógenos.
Resultados contrários foram verificados por Ricci et al. (2010) que trabalharam com solo tratado com lodo de esgoto. Kitamura et al. (2008) e Alves \& Souza (2008) estudaram o comportamento da recuperação de áreas degradadas com as mesmas características e verificaram aumento nos valores do $\mathrm{pH}$ quando utilizado adubo verde para aumentar a matéria orgânica do solo.

Observou-se, para $\mathrm{H}+\mathrm{Al}$, que a área cultivada com eucalipto e tratada com a dose de $30 \mathrm{Mg} \mathrm{ha}^{-1}$, testemunha e adubação mineral, obteve resultados menores (Tabela 6), fato este devido os solos de cerrado apresentarem, como característica, acidez elevada, baixo teor de MO e baixos valores de P (Bonini, 2012).

Em seus estudos, Ricci et al. (2010) verificaram, utilizando doses $\left(0,20,40\right.$ e $\left.80 \mathrm{Mg} \mathrm{ha}^{-1}\right)$ de um composto orgânico de lodo de esgoto e resíduos de roçagem na recuperação de um solo decapitado, que não houve influência do lodo de esgoto na redução da acidez potencial.

Em relação à SB observou-se que o tratamento com o solo exposto apresentou os menores valores da SB seguido pela vegetação natural de Cerrado. Já para a camada de 0,20 $0,40 \mathrm{~m}$ não houve diferenças entre os tratamentos (Tabela 7). Analisando a CTC verificou-se que, tal como na SB, houve incrementos em virtude da adição de cátions trocáveis proporcionada pela calagem e aplicação de lodo de esgoto (Tabelas 6 e 7).

As doses de lodo de esgoto e a adubação mineral com relação ao V\% promoveram aumento devido aos tratamentos de recuperação, sendo que na área cultivada com eucalipto e tratada com a dose de $30 \mathrm{Mg} \mathrm{ha}^{-1}$ foi a que obteve melhores resultados (Tabelas 6 e 7). Colodro \& Espíndola (2006) verificaram, na mesma área e na camada de 0,00-0,05 m, resultados semelhantes para a $\mathrm{V} \%$. O aumento do $\mathrm{pH}$ corrobora com os dados obtidos para a V\% que foram maiores nos tratamentos com lodo de esgoto e adubação mineral, explicado 
pela substituição dos íons $\mathrm{H}^{+}$e $\mathrm{Al}^{+3}$ pelas bases trocáveis $\left(\mathrm{Ca}^{+2}\right.$, $\mathrm{Mg}^{+}, \mathrm{K}^{+}$) nos sítios de troca do solo.

\section{Conclusões}

1. O lodo de esgoto influenciou positivamente os atributos químicos do solo estudados ( $\mathrm{pH}, \mathrm{CTC}, \mathrm{SB}, \mathrm{MO}, \mathrm{P}, \mathrm{Ca}, \mathrm{Mg}$ e K).

2. Os teores de fósforo, matéria orgânica e saturação por bases, foram bons indicadores da qualidade química do solo.

3. A dose de $60 \mathrm{Mg} \mathrm{ha}^{-1}$ foi o tratamento com melhor resultado indicado pelo incremento de $\mathrm{MO}$ e bases trocáveis do solo enquanto a testemunha vegetação nativa obteve os melhores resultados para os demais atributos do solo

\section{Agradecimentos}

Os autores agradecem à FAPESP e ao CNPq, pela concessão das Bolsas de Iniciação Científica.

\section{Literatura Citada}

Alves, M. C.; Souza, Z. M. Recuperação de área degradada por construção de hidroelétrica com adubação verde e corretivo. Revista Brasileira de Ciência do Solo, v.32, p.2505-2516, 2008. http://dx.doi.org/10.1590/S0100-06832008000600027

Alves, M. C.; Suzuki, L. G. A. S.; Suzuki, L. E. A. S. Densidade do solo e infiltração de água como indicadores da qualidade física de um Latossolo Vermelho distrófico em recuperação. Revista Brasileira de Ciência do Solo, v.31, p.617-625, 2007. http://dx.doi. org/10.1590/S0100-06832007000400002

Barboza, G. M. C.; Tavares Filho, J. Uso agrícola do lodo de esgoto: influência nas propriedades químicas e físicas do solo, produtividade e recuperação de áreas degradadas. Semina: Ciências Agrárias, v.27, p.565-580, 2006. http://dx.doi. org/10.5433/1679-0359.2006v27n4p565

Berton, R. S.; Camargo, O. A.; Valdares, J. M. A. S. Absorção de nutrientes pelo milho em resposta à adição de lodo de esgoto a cinco solos paulistas. Revista Brasileira de Ciência do Solo, v.13, p.187-192, 1989.

Bonini, C. S. B. Restauração ecológica de um solo decapitado sob intervenção antrópica há 17 anos . Ilha Solteira: FEIS/UNESP, 2012. 167p. Tese Doutorado

Brasil. Ministério do Meio Ambiente, Conselho Nacional de Meio Ambiente, CONAMA. Resolução CONAMA n³75, de 29 de agosto de 2006. Disponível em: http://www.mma.gov.br/port/ conama/res/res06/res37506.pdf. 10 Jan. 2014.

Campos, F. da S.; Alves, M. C. Uso de lodo de esgoto na reestruturação de solo degradado. Revista Brasileira de Ciência do Solo, v.32, p.1389-1397, 2008. http://dx.doi.org/10.1590/S010006832008000400003

Colodro, G.; Espíndola, C. R. Alterações na fertilidade de um latossolo degradado em resposta à aplicação de lodo de esgoto. Acta Scientiarum. Agronomy, v.28, p.1-5, 2006.
Costa, V. L.; Maria, I. C.; Camargo, O. A.; Grego, C. R.; Melo, L. C. A. Distribuição espacial de fósforo em Latossolo tratado com lodo de esgoto e adubação mineral. Revista Brasileira de Engenharia Agrícola e Ambiental, v.18, p.287-93, 2014. http:// dx.doi.org/10.1590/S1415-43662014000300007

Demattê, J. L. I. Levantamento detalhado dos solos do Campus Experimental de Ilha Solteira (SP). Piracicaba: Esalq, 1980. 131p.

EMBRAPA - Empresa Brasileira de Pesquisa Agropecuária. Centro Nacional de Pesquisa de Solos. Sistema brasileiro de classificação de solos. Rio de Janeiro: EMBRAPA, 2013. 306p.

Ferreira, D. F. SISVAR: Um programa para análises e ensino de estatística. Revista Symposium, v.6, p.36-41, 2008.

Kitamura, A. E.; Alves, M. C.; Suzuki, L. G. A. S.; Gonzalez, A. P. Recuperação de um solo degradado com a aplicação de adubos verdes e lodo de esgoto. Revista Brasileira de Ciência do Solo, v.32, p.405-416, 2008. http://dx.doi.org/10.1590/S010006832008000100038

Mello, F. A. F.; Brasil Sobrinho, M. D. C.; Arzolla, S.; Silveira, R. I.; Etto, A. C.; Kiehl, J. C. Fertilidade do solo. 2.ed. São Paulo: Nobel, 1983. 401p.

Muraishi, C. T.; Alves, M. C.; Silva Júnior, A.; Souza, Z. M. Chemical attributes of a savannah Typic Hapludox soil under management systems. Acta Scientiarum. Agronomy, v.33, p.551-557, 2011. http://dx.doi.org/10.4025/actasciagron.v33i3.6593

Pedroza, M. M.; Vieira, G. E. G.; Sousa, J. F.; Pickler, A. C.; Leal, E. R. M.; Milhomen, C. C. Produção e tratamento de lodo de esgoto Uma revisão. Revista Liberato, v.11, p.89-188. 2010.

Raij B. van.; Quaggio J. A. Métodos de análises de solo para fins de fertilidade. Campinas: Instituto Agronômico de Campinas, 1983. 31 . Boletim Técnico, 81.

Ricci, A. B.; Padovani, V. C. R.; Paula Júnior, D. R. Uso de lodo de esgoto estabilizado em um solo decapitado: II - Atributos químicos e revegetação. Revista Brasileira de Ciência do Solo, v.34, p.543551, 2010. http://dx.doi.org/10.1590/S0100-06832010000200028

Rodrigues, B. R.; Maltoni, K. L.; Cassiolato, A. M. R. Dinâmica da regeneração do subsolo de áreas degradadas dentro do Bioma Cerrado. Revista Brasileira de Engenharia Agrícola e Ambiental, v.11, p.73-80, 2007. http://dx.doi.org/10.1590/S141543662007000100010

Schiavoni, E. A.; Alves, M. C.; Souza, Z. M.; Costa, F. G. Influence of organic-mineral fertilization of an oxisol on soil chemical properties and Bracharia brizantha production. Revista Brasileira de Ciência do Solo, v.35, p.2219-2226, 2011. http://dx.doi. org/10.1590/S0100-06832011000600037

Soccol, V. T.; Castro, E. A.; Paulino, R. Manual de métodos para análises parasitológicas em reciclagem de lodo. Curitiba: SANEPAR, 2000. p.27-41.

Suzuki, L. E. A. S.; Alves, M. C. Fitomassa de plantas de cobertura em diferentes sucessões de culturas e sistemas de cultivo. Bragantia, v.65, p.121-127, 2006. http://dx.doi.org/10.1590/S000687052006000100016 